\title{
Reframing the professional ethic: the Council of Medical Specialty Societies consensus statement on the ethic of medicine
}

Sara C Charles
Department of
Psychiatry
University of Illinois
School of Medicine
912 S Wood St (M/C
913 )
Chicago, IL 60612
Jeremy A Lazarus
University of Colorado
Health Sciences Center
4200 E Ninth Ave
Denver, CO 80262
Workgroup on the Ethic
of Medicine
Council of Medical
Specialty Societies
For a list of workgroup
leaders and members and
their specialty society
affiliations, please see the
wjm web site at
http://www.ewjm.com.
Correspondence to:
Dr Charles
scharlesmd@ @ompuserve.
com
Competing interests:
None declared
Funding: The conference
was supported in part by
the John Templeton
Foundation;
Northwestern Healthcare
Network, Chicago;
Robert Wood Johnson
Foundation, Princeton,
NJ; Milbank Memorial
Fund, New York; and
the King Kullen
Company, Bethpage, NY

Sara C Charles

University of Illinois

School of Medicine

S Wood St $(\mathrm{M} / \mathrm{C}$

Chicago, IL 60612

Jeremy A Lazarus

4200 E Ninth Ave

Denver, CO 80262

Workgroup on the Ethic

their specialty society

affiliations, please see the

wjm web site at

Correspondence to:

Dr Charles

scharlesmd@compuserve.

com

Competing interests:

None declared

Funding: The conference

Foundation;

Northwestern Healthcare

Foundation, Princeton,

NJ; Milbank Memorial

Fund, New York; and

the King Kullen

West J Med

2000;173:198-201

\section{INTRODUCTION}

"Ethics makes us more critical of what we are doing-to bring us back daily to thinking about what it is to be a good doctor." ${ }^{\text {(p38) }}$

Physicians are finding it difficult to apply ethical principles in an environment in which the views of their responsibilities are constantly shifting. Clinical decision making, the core of medical work, is influenced by competing interests, including those that are sometimes critical to physicians' livelihood. Does some common purpose remain in medical work that provides direction toward balancing these interests and clarifying physicians' responsibilities?

Traditional medical ethics, as embodied in the American Medical Association's Code of Medical Ethics (hereafter, the AMA Code of Ethics), has served as an ethical guide since the mid-1840s and has focused on physicians' responsibility to individual patients. ${ }^{2}$ But the code fails to address other physician obligations adequately, such as providing universal access to health care and preventive services. Many observers, therefore, have called for a new ethic. ${ }^{3-6}$

\section{CONSENSUS STATEMENT OF THE COUNCIL OF MEDICAL SPECIALTY SOCIETIES}

The Council of Medical Specialty Societies (CMSS), an organization of national medical specialty societies, in 1995 established a task force on the ethic of medicine, culminating in a consensus statement in 1997 that was formulated by practicing physicians.

The consensus statement's 11 principles are prefaced by a preamble and framed in terms of physicians' relationships. Explanatory comments integral to each principle are contained in the complete statement (available at www. cmss.org). Rather than being a definitive document or supplanting any specialty society's code, the hope is that this statement of principles will provoke further discussion about, and the development of, an ethical foundation of medical care in an increasingly complex environment.

\section{CMSS CONSENSUS STATEMENT ON THE ETHIC OF MEDICINE Physician-patient relationship}

1 The physician's primary inviolate role is as an active advocate for each patient's care and well-being.

\section{Summary points}

- Ethical principles are difficult to apply in today's constantly changing environment of health care

- An ethic of medicine must seek to balance physicians' obligation to individual patients with the professional, collective obligation to all who need medical care

- Physicians in both clinical and nonclinical work should remain focused on patients

- Terminally ill patients present complexities in care that require special ethical considerations

- We present a framework for ethical reflection that was developed by and for practitioners

\section{Preamble}

The practice of medicine is rooted in a covenant of trust among patients, physicians, and society. The ethic of medicine must seek to balance the physician's responsibility to each patient and the professional, collective obligation to all who need medical care. This statement articulates core values and principles that are shared by all physicians, in a range of settings and circumstances, including the use of new technologies of communication, regardless of specialty.

2 The physician should treat each patient with honesty, compassion, dignity, and respect for individual autonomy.

3 The physician's commitment to patients includes health education and continuity of care.

\section{Physician-physician relationship}

4 Physicians have a responsibility to maintain moral integrity, intellectual honesty, and clinical competence.

5 Physicians, as stewards of medical knowledge, have an obligation to educate and share information with colleagues, including physicians in training.

\section{RELATIONSHIP OF THE PHYSICIAN TO SYSTEMS OF CARE}

6 The physician's duty of patient advocacy should not be altered by the system of health care delivery in which the physician practices. 
7 Physicians should resolve conflicts of interest in a way that gives primacy to the patient's interests.

8 Physicians should provide knowledgeable input into organizational decisions on the allocation of medical resources and the process of health care delivery.

\section{Relationship of physician to society}

9 Physicians have an obligation to serve the health care needs of all members of society.

10 Physicians have an ethical obligation to participate in the formation of health care policy.

11 Physicians have an ethical obligation to preserve and protect the trust bestowed on them by society.

Some of the values and principles that impinge on the relationship of physicians to their patients, colleagues, organizations, and the larger society in which they practice are introduced in this document. Further specifications can be developed to fit the particular needs of individual specialties, patient groups, and practice circumstances.

\section{HOW CAN PHYSICIANS SERVE INDIVIDUAL PATIENTS AND SOCIETY?}

A palpable tension permeates the consensus statement. Dr Edmund Pellegrino, the well-known medical ethicist, notes that physicians' obligations to both individual patients and to society are currently in conflict. Until this is resolved, physicians must remain focused on the patient, the foundation of the profession's ethical obligations, and cannot function as a double agent. ${ }^{1,7}$

Brody, however, argues that this patient-centered ideal is a "comforting myth," but one too far removed from reality to serve as a moral guide in times of such complex challenges to medical professionalism. ${ }^{8}$ Hall and Berenson suggest as more realistic a group-based ethic that would encourage physicians to do the best they can with the resources available for their own patients and for others within the same practice group or insurance plan. ${ }^{5}$ In addition, Bloche, a physician, lawyer, and ethicist, observes that physicians often work not directly with patients but within the justice system, insurance industry, and other social institutions. This paradigm of practice suggests that work for third parties creates no physicianpatient relationship and, therefore, no primary obligation to the patient. This would appear to exempt physicians who ostensibly serve some societal goal from traditional ethical obligations., ${ }^{2,9,10}$ Physicians who perform preauthorization reviews, for example, might not be held to the same ethic as those working directly with patients. Some states, however, have passed legislation that holds physicians serving as "medical directors" to the same obligations as treating physicians.
The authors of the CMSS statement maintain the primacy of physicians' duties toward patients even when they function outside of direct patient care (AMA Code of Ethics: opinion 8.02). ${ }^{2}$ The final sentence in the preamble flows from this ideal: that all physicians as a group share core values and principles irrespective of their specialty, work setting, or circumstances of practice.

\section{Case history}

Dr Manville, a 55 -year-old oncologist, is treating a terminally ill cancer patient with routine pain medication. A new medication that costs twice as much comes on the market and is advertised as providing better pain management. If $\mathrm{Dr}$ Manville chooses to prescribe the newer medication, his compensation from both his practice group and the managed care company that insures his patient will be affected. Is he obligated to disclose these financial arrangements to the patient? Dr Manville, in his best informed medical judgment, believes that the newer medication is not significantly better and decides against prescribing it. What if the patient demands the more expensive medication? What if the patient asks Dr Manville for an amount of the routine medication that could result in death if taken in overdose? If Dr Manville refuses, and the patient asks to be referred to a physician who might prescribe that amount of medication, what should Dr Manville do?

\section{DISCUSSION OF CASE}

Three consensus statement principles apply to this case:

\section{Principle 7}

A comment to principle 7 states "conflicts of interest are inevitable in medical practice. Physicians should disclose conflicts of interest to their patients, inform them of the impact of these conflicts on their medical care and of the options for their resolution."

If Dr Manville determines that the difference in efficacy between the current and new medication is insignificant, and he chooses not to prescribe the new one, financial disclosure is unnecessary. However, if his personal financial interest was a contributing factor in his decision, he would have to declare this to his patient.

If the data show that the new medication is more effective than the current one, Dr Manville is ethically obligated to consider prescribing it. Dr Manville must assess carefully the financial motivations in whatever decision he makes, and he must disclose these to the patient. As his patient's advocate, he should seek to include the medication in the formulary. Failing this, he should inform the patient of the drug's efficacy, its cost, and his financial conflict. Failure to prescribe the better medication because of income considerations or the hassle in- 


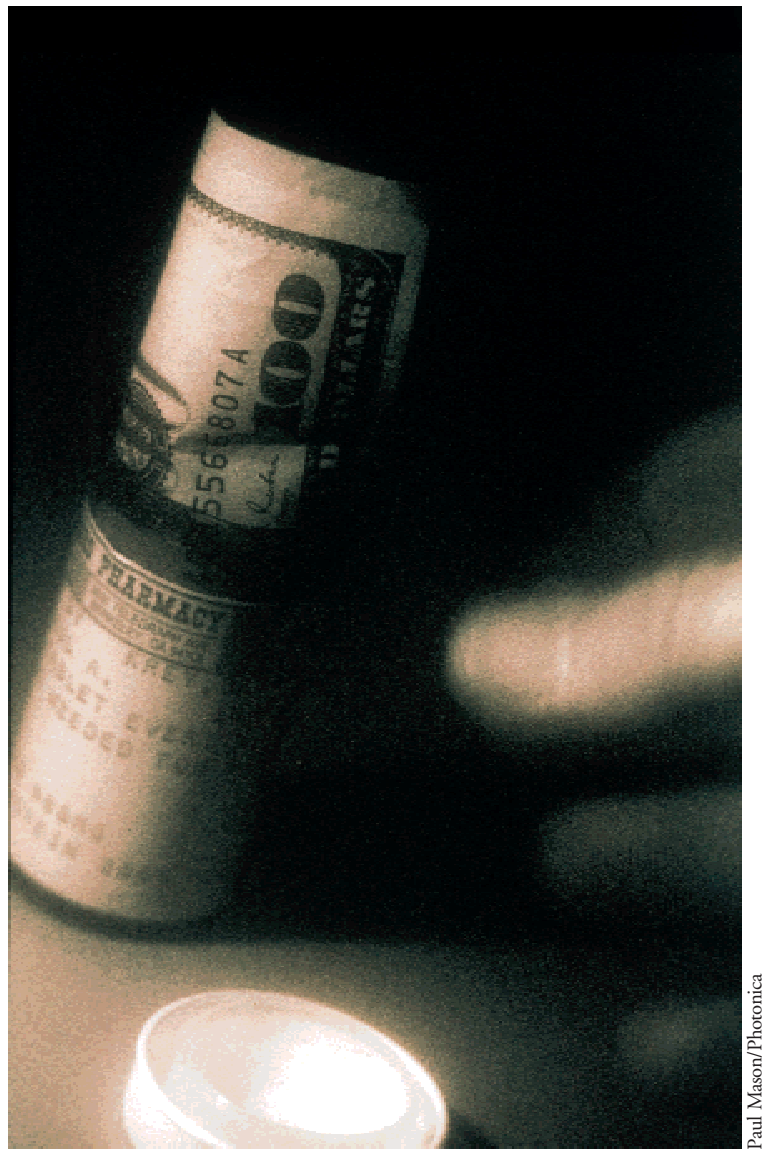

Doctors have a duty to prescribe the most effective drug, even if it costs more

volved is ethically unacceptable. If the patient is unable to pay out-of-pocket expenses, Dr Manville may opt to prescribe it, accept the financial loss, and continue to lobby for its inclusion in the formulary.

Consensus statement authors support the current AMA opinion that obligates physicians to disclose both treatment options and financial incentives. ${ }^{11}$ Some authors suggest that physicians are ill-equipped to explain their financial arrangements to patients and, in disclosing them, may undermine rather than enhance trust. These authors would place the obligation of the disclosure of financial concerns on the managed care plans rather than on physicians. ${ }^{12}$

Does joining a health maintenance organization, therefore, constitute a tacit agreement by the patient that there will be some limitations on the provision of medical care? Bloche suggests that disclosure either by the plan or by the physician does not dispense with the primary obligation of fidelity to the patient. ${ }^{9}$

\section{Principle 8}

A comment to principle 8 states that "physicians should advocate for the adoption of organizational policies that facilitate access to basic medical care." Dr Manville, therefore, is obligated to advocate for additions to the formulary if his patient will benefit materially. The AMA opinions on managed care and on prescription policies (AMA Code of Ethics: opinions 8.135 and 8.13) provide useful guidelines for physicians and managed care organizations. ${ }^{2}$ Managed care companies should allow for sufficiently broad prescription guidelines and for the inclusion of new effective drugs. Physicians should read their contracts carefully regarding pharmaceutic use and appeal mechanisms. If a contract fails to provide a mechanism for implementing medical advances, for example, the plan may force physicians to practice below minimum standards and ethically require them to resign (AMA Code of Ethics: opinion $8.13-2 \mathrm{G})^{2}$

\section{Principle 2}

In this case, after Dr Manville informed the patient that the difference in the drugs was insignificant, the patient remained adamant about trying the new medication. A comment to principle 2 states that "the physician should remain compassionate and dedicated to patients at the end of life, advise them and their surrogates of available options to alleviate pain and suffering, and use life-sustaining therapy appropriately." This comment does not imply that physicians necessarily should suffer financially in working to achieve these goals, but does alert them to the special needs of dying patients. Given recent advances in pain control, physicians are ethically bound to possess accurate and current knowledge about these medications. ${ }^{13}$

Dr Manville presumably has this knowledge, but out of concern and sensitivity to the patient, he may agree to a course of the new medication and absorb the financial loss. If, on the other hand, he continues to refuse and the patient requests enough routine medication to kill himself, Dr Manville should discuss his own ethical approach to the issue of physician-assisted suicide with both the patient and the patient's surrogates. In respecting the patient's wishes, autonomy, and values, the physician is under no obligation to refer a patient explicitly for what he would assess to be an unethical procedure. If the patient is dissatisfied with Dr Manville's response and no longer wants to continue as his patient, Dr Manville is free to provide the patient with a list of other physicians for treatment.

The consensus statement not only supports full, empathic communication with all patients but explicitly identifies terminally ill patients who, for various reasons, are particularly vulnerable to neglect by physicians. The statement does not explicitly discuss physician-assisted suicide, which occurs when a physician facilitates the patient's death by providing either information or the means of the patient's effecting a life-ending act (AMA Code of Ethics: opinion 2.211), ${ }^{2}$ but it does obligate physicians to 
be well informed about advances in this field. This allows them to competently and sensitively assist dying patients and their loved ones.

In this age of managed care, physicians must guard against "abusing" patients in new ways by allowing them to receive suboptimal treatment. ${ }^{14}$ In a recent California case, for example, a physician was charged with "elder abuse" for allegedly failing to adequately treat a dying man's pain. ${ }^{15}$ There is evidence that when physicians take the time to inform the patient and family about pain control and other supportive end-of-life measures, the patient usually opts to receive appropriate interventions and to continue receiving care by the treating physician. ${ }^{16}$

\section{CONCLUSION}

In this article, we demonstrate an application of the comments and the principles contained in the CMSS consensus statement on the ethic of medicine. The goal is to provide a model for ethical reflection on the problems that arise in everyday practice.

The Council of Medical Specialty Societies staff includes Rebecca Gschwend and Jan Narby.
References

1 Pellegrino ED, Thomasma DC. The Virtues in Medical Practice. New York: Oxford University Press; 1993.

2 Code of Medical Ethics. Chicago: American Medical Association; 1997.

3 Wright AP. How pliable are the principles? Am Med News April 12, 1999, pp 9-11.

4 Kassirer JP. Managing care-should we adopt a new ethic? [editorial] $N$ Engl J Med 1998;339:397-398.

5 Hall MA, Berenson RA. Ethical practice in managed care: a dose of realism. Ann Intern Med 1998;128:395-402.

6 Wolf SM. Health care reform and the future of the physician's ethic. Hastings Cent Rep 1994;24:28-41.

7 Pellegrino ED. Interests, obligations, and justice: some notes toward an ethic of managed care. J Clin Ethics 1995;6:312-317.

8 Brody H. A new ethic for medicine? [letter] $N$ Engl J Med 1998;339:1327.

9 Bloche MG. Clinical loyalties and the social purpose of medicine. JAMA 1999;281:268-274.

10 Applebaum P. The parable of the forensic psychiatrist: ethics and the problem of doing harm. Int J Law Psychiatry 1990;13:249-259.

11 Council on Ethical and Judicial Affairs. Ethical issues in managed care. JAMA 1995;273:330-335.

12 Mechanic D, Schlesinger M. The impact of managed care on patients' trust in medical care and their physicians. JAMA 1996;275:1693-1697.

13 Pellegrino ED. Emerging ethical issues in palliative care. JAMA 1998;279:1521-1522

14 Kluft RP. The physician as perpetrator of abuse. Prim Care 1993;20:459-480

15 Foubister V. Doctor faces charges for allegedly undertreating pain. Am Med News March 20, 2000, p 11.

16 Van Der Maas PJ, Van Delden JJ, Pijnenborg L, Looman CWN Euthanasia and other medical decisions concerning the end of life. Lancet 1991;338:669-674.

\section{Netphiles}

\section{Angioplasty}

A meta-analysis has shown that although angioplasty for coronary artery disease reduces anginal symptoms in comparison with drug therapy, it seems to do so at the cost of an increased risk of infarction, death, and the need for surgery (BMJ 2000;321:73-77).

Both Google (www.google.com) and Altravista (www.av.com) reveal that there are about 10,200 pages with the phrase "coronary angioplasty" on them, a completely unworkable amount of information that hints at the difficulty of getting the results of research into practice. The difficulty of persuading 10,200 authors to revise and update their pages is exceeded only by the difficulty of getting doctors around the world to change their practice.

The pages at www.americanheart.org/Heart_and_Stroke_A_Z_Guide/angioc.html show that almost half a million coronary angioplasties were performed in the United States in 1997 and—whatever the evidence base—an industry like that does not shut down overnight.

Perhaps a certain amount of friction in the system is a good thing: a world in which the publication of a trial 1 day led to an instant revolution in practice the next would be a difficult place in which to live.

Consumer health information about coronary angioplasty is not hard to find. You can download Quicktime movies about having an angioplasty at www.northmemorial.com/nmhc/services/heart/animate.htm. The size of the download will depend on how you set up your Quicktime plug-in (which itself may have to be downloaded). Still, it's worth the wait, with clear animated illustration of the basic anatomic principles and an explanatory soundtrack. And while we're exclaiming at the power of Quicktime, have a look at www.uscuh.com/tour/quicktime/cardiac/cardiac_main.html, a three-dimensional representation of a coronary catheter lab that uses Quicktime VR (virtual reality) to provide a virtual guided tour. Gimmicky perhaps, but used as part of the pre-procedure preparation, it might reduce anxiety.

Douglas Carnall dcarnall@bmj.com
We welcome suggestions for Web sites to be included in future Netphiles 